EPiC Series in Language and Linguistics
Volume 2, 2017, Pages 1-13
$\begin{gathered}\text { Professional and Academic Discourse: } \\ \text { an Interdisciplinary Perspective }\end{gathered}$

\title{
Interdisciplinary Cooperation in the Analysis of Specialized Discourse: Challenges and Prospects
}

\author{
Maurizio Gotti \\ Università di Bergamo, Italy \\ maurizio.gotti@unibg.it
}

\begin{abstract}
The purpose of this paper is to investigate some of the challenges and prospects connected with interdisciplinary cooperation in the analysis of specialized discourse. In the last few decades, the ESP literature has often underlined the importance of this type of collaboration, highlighting the usefulness of the integration of methodological diversity, the exploration of possible connections among procedures and knowledge in order to achieve more focused interpretation and purposeful action. This interdisciplinary process is considered fundamental to better understand how practitioners use language to achieve the objectives of their professions.

However, this collaborative experience may also present serious challenges both to the applied linguist and the expert professional, which can only be faced by means of a careful alignment of the specialist's perspective with the analyst's approach, and a continuous process of feedback and triangulation that guarantees inter-analytic reliability of the research project. This negotiation of the findings also avoids the insurgence of the practitioners' skepticism towards the research results and therefore their limited impact on professional practice.
\end{abstract}

\section{Introduction}

The close cooperation between applied linguists and professional experts has become well established in the research literature of both fields. The past few decades have seen the implementation of several projects aiming to investigate the communicative practices adopted in different workplaces. This collaboration has taken various forms and has been carried out at different levels: in research projects involving colleagues from other academic disciplines or expert professional practitioners; in consultancy work commissioned by service providers or policy makers.

The necessity for a joint analysis of a specialized text with applied linguists is strongly felt by specialists themselves, who often experience the need to apply appropriate linguistic analyses in order to interpret correctly passages presenting difficulties of interpretation. The reason which particularly stimulates them to seek the linguist's help is that the form of a text matters just as much as its contents. 
This thorough investigation of specialized discourse strengthens the specialist's interpretive skills and greatly improves his critical activity. The employment of such exegetic techniques is therefore greatly appreciated, and is subsequently felt to be a necessary part of the specialist's approach. As McCloskey states:

The ignorance of rhetoric leaves economists unable to confront doubts, really confront them. Run another regression that no one else believes. Deduce another consequence that no one else is persuaded by. Adduce another institutional fact that no one else sees as relevant. (McCloskey 1988: 287)

Thus, the linguist's contribution is particularly appreciated when it succeeds in explaining the way the specialist has chosen to construct and express the contents of the text examined. The results of his analysis do not only provide the specialist with the useful elements required for a better interpretation of the text and therefore for subsequent theoretical or applied activity, but they may also provide the linguist with deeper and newer insights as regards the features of the register and discourse that he is analyzing. Indeed, collaborative interpretive practices may provide the applied linguist with a useful opportunity to reflect on one's own assumptions regarding particular discursive practices.

Relying on his extensive collaborative experience, Sarangi (2015) finds that apart from the existing notions of communities of practice, communities of discourse (or discourse communities) and communities of interpretation (or interpretive communities), the notion of 'communities of interest' should be introduced to better characterize the type of interprofessional collaboration in which he has been engaged. According to Sarangi (2015: 28-29), the construct of 'communities of interest' "acknowledges differences in ontologies and epistemologies across given communities of practice/discourse/interpretation, but privileges the mutual interest in the phenomena under study. [...] 'Communities of interest' concern scenarios in which one crosses different communities of discourse/interpretive practice - where one may share 'interests' but not 'practices', 'discourses' and 'interpretations'.”

In order to better understand the discourse of a particular workplace, it is imperative that such practices should be viewed in the context of their local organizational conditions and their institutional histories. As Cicourel (1992: 294) writes:

Verbal interaction is related to the task in hand. Language and other social practices are interdependent. Knowing something about the ethnographic setting, the perception of, and characteristics attributed to, others, and broader and local organisational conditions becomes imperative for an understanding of linguistic and non-linguistic aspects of communicative events.

Therefore, in analyzing professional discourse it is essential to focus also on the conditions of production and reception of the texts, as well as their links to activity and practice, since activity and discourse are always tightly linked. In this analytical process, the contribution of professional experts is particularly relevant, as well highlighted by Clarke (2005: 189):

Interpretation of professional behaviour, and especially any attempt to evaluate professional practice, can only sensibly proceed with some input from the professionals. This is not to say that a professional's account of their practice must be taken at face value [...] but an attempt to make sense of practice without some input from professionals is unlikely to be productive.

This is the reason why an applied linguist's various findings should be continuously confronted with the expert professional in a process of feedback and triangulation (Cicourel 1992) in order to assess inter-analytic reliability whenever possible. This collaborative interpretation by members of the same 'community of interest' may also help minimize what Sarangi (2002) called 'the analyst's paradox', i.e. the risk of leaving researchers to depend on the insights of the practitioner to inform the data analysis. Indeed, "collaborative interpretation does not privilege participant perspectives unduly: instead it tries 
to align participant's perspective with analyst's perspective” (Sarangi 2002: 121-122). The continuous negotiation of the applied linguist's findings also avoids the insurgence of the practitioners' skepticism towards the research results and therefore their limited impact on professional practice. Moreover, this collaborative approach may compensate the linguist's lack of adequate knowledge of another discipline.

The purpose of this paper is to investigate some of the challenges and prospects connected with interdisciplinary cooperation in the analysis of specialized discourse. In order to better assess the high value provided by an intense cooperation between applied linguists and professional experts in the analysis of specialized discourse, the following sections will present and discuss a specific interdisciplinary research, which will show how a careful analysis of both the text and its context has proved to be successful in helping specialists to understand the use of specialized discourse in a specific professional context.

\section{The Analysis of Keynes' Text}

John Maynard Keynes was certainly the single most influential economist of the twentieth century. He revolutionized economics with his classic book, The General Theory of Employment, Interest and Money (henceforth GT), ${ }^{1}$ which is commonly regarded as the most influential economic treatise of the past century, in that it changed the way the world looked at the economy and the role of government in society. Indeed, with this book, he constructed the fundamental relationships and ideas behind what became known as 'macroeconomics'. The GT was immediately and widely successful and it further confirmed Keynes' popularity and intellectual prominence. From the very start, the book caught the attention of economists and was generally accepted as a landmark in economic thought. As Keynes had hoped, the revolutionary significance of his work was soon acknowledged. Nevertheless, a few economists have found difficulties in understanding Keynes' discourse and have expressed criticism of its textual obscurity and ambiguity, which are considered the cause of both misunderstandings and divergent interpretations. In some cases the criticism has been very harsh indeed:

Keynes, likewise, hardly deserves credit for what he supposedly may have meant but did not know how to say. If, more than 50 years later, scholars are still disputing the central message of the General Theory, that very fact should count against rather than in favour of Keynes's claims to scientific stature. Whatever the General Theory was, it was not great science. It was largely a dressing-up of old fallacies. Worse, for many years it crowded better science off the intellectual scene. (Yeager 1986: 40)

This disapproval of Keynes' writing is in many ways perplexing, as elsewhere it has been highly praised for its elegance and clarity. ${ }^{2}$ Therefore, when examining why economists blame the GT of being badly written, one should take into consideration two alternative explanations: on the one hand, that Keynes deliberately diverged from the normal rules of economic discourse and its register instead of adhering to his audience's expectations; on the other hand, that economists themselves may have decoded Keynes' writing incorrectly.

To investigate the alleged inconsistencies and misinterpretations of this text, an interdisciplinary research project was proposed by various economists, who contacted some linguists commonly working

\footnotetext{
${ }^{1}$ The General Theory of Employment, Interest, and Money (London: Macmillan, 1936) is cited here from The Collected Writings of John Maynard Keyes (Vol. VII, London: Macmillan, 1973), whose various volumes are referred to by the initials CW.

${ }^{2}$ See, for example, the following statement: "There are constant reminders throughout the [GT] that we are in the presence of a master of English style. The language is generally rich and incisive, enhanced occasionally by well-turned phrases and apt literary allusions. For Keynes' objective is to appeal not only to the intellect but also to the esthetic senses" (Patinkin 1976: 24).
} 
on the analysis of economic discourse (among whom I was one) in order to reach a better interpretation of this text, and thus confront the problem of the various existing readings of the GT.

\subsection{Keynes' Use of Terminology}

The first aspect that caught the linguists' attention was Keynes' use of specialized terminology. Indeed, the GT contains various exceptions to the criteria which are commonly followed in the use of domain-specific vocabulary. For example, it frequently violates the principle of monoreferentiality (Gotti 2011), as shown by the presence of many cases of ambiguity and polysemy. This appears to be the result of a deliberate decision, as Keynes clearly asserts that he disagrees with the use of monoreferential language because of its excessive rigidity and inability to describe complex phenomena in an adequate manner. He argues that:

(1) too large a proportion of recent 'mathematical' economics are merely concoctions, as imprecise as the initial assumptions they rest on, which allow the author to lose sight of the complexities and interdependencies of the real world in a maze of pretentious and unhelpful symbols. (GT: 298)

According to Keynes, what makes formal economic language inappropriate for the discussion of theoretical issues is that the univocal reference of each lexical term to a specific concept does not take into account the need to give words different meanings in different contexts and at different points in the discourse. The complexity and interconnectedness of elements within his argumentation do not permit atomistic analysis. In his own words:

(2) It is a great fault of symbolic-mathematical methods of formalising a system of economic analysis [...] that they expressly assume strict independence between the factors involved and lose all their cogency and authority if this hypothesis is disallowed; whereas in ordinary discourse, where we are not blindly manipulating but know all the time what we are doing and what the words mean, we can keep 'at the back of our heads' the necessary reserves and qualifications and the adjustments which we shall have to make later on, in a way in which we cannot keep complicated partial differentials 'at the back' of several pages of algebra which assume that they all vanish. (GT: 297-8)

Translating thoughts into the precise, unequivocal terms of a symbolic-mathematical language is for Keynes an obstacle to their development, as the continuous conceptual changes of economic reasoning require a more flexible expressive system that allows for constant redefinition of the terms' referents. This inadequacy leads Keynes to view symbolic-mathematical language as a source of confusion and misunderstanding, due not to specialized discourse itself (which is extremely precise and semantically transparent) but to the fact that it is used (with unsatisfactory results) in a non-positivistic discipline such as economics while it was developed for the positivistic sciences, i.e. those branches in which univocal references to phenomena and concepts highlight the objective referential function.

Another element which has caused ambiguity in Keynes' text is his rather peculiar use of economic terminology. Insofar as the reader has a reasonable expectation that, once a technical term has been introduced in one sense, it will continue to be used in that way until the author should decide otherwise, Keynes' attitude here can be regarded as an infringement of those expectations. Indeed, a close reading of the GT shows that terms are not always monoreferential but rather may refer to different concepts. One of these, for example, is the expression aggregate demand function, which is used in the book to refer "both [to] the level of demand which producers expect in order to form their output strategy - to find the point on their supply curves where they expect to maximize their profits - and aggregate demand as it is manifested in the marketplace” (Chick 2006: 146). In other cases Keynes uses two different terms for the same concept; as the use of two words commonly implies two meanings, the 
reader is led to believe that the concepts are not the same. Keynes is aware of his ambiguous use of terminology, yet he considers this an essential part of his methodological ${ }^{3}$ position:

(3) A definition can often be vague within fairly wide limits and capable of several interpretations differing slightly from one another, and still be perfectly serviceable and free from serious risks [...], provided that [...] it is used consistently within a given context. If an author tries to avoid all vagueness and to be perfectly precise, he will become [...] prolix and pedantic. (CW XXIX: 36)

Instead of employing a defining process of the prescriptive type (Naess 1981) Keynes seems to prefer the descriptive type, which avoids a clear-cut relationship between definiens and definiendum. Although he feels that new terms are often a necessity when writing an argumentative text, the defining process is perceived as a constraint to his creativeness and as a considerable limitation to the decoder's intuitive possibilities. In a letter to R.B. Bryce, Keynes confirms this belief:

(4) In my book I have deemed it necessary to go into [definitions] at disproportionate length, whilst feeling that this was in a sense a great pity and might divert the readers' minds from the real issues. It is, I think, a further illustration of the appalling state of scholasticism into which the minds of so many economists have got which allows them to take leave of their intuitions altogether. Yet in writing economics one is not writing either a mathematical proof or a legal document. One is trying to arouse and appeal to the reader's intuitions; and, if he has worked himself into a state when he has none, one is helpless. (Quoted in Patinkin/Leith 1977: 128)

Restricting the meaning of words to certain specific aspects of the reality referred to greatly limits their expressive potential, making their interpretation incomplete and at times erroneous. Keynes thus endows his terms with interpretational subjectivity because the extreme variability of their referents is more appropriate to his dynamic view of the economic system. As will be seen in greater depth below, his emphasis on the intrinsic dynamism of the various phenomena and on the interplay among the various economic factors dictate an overcoming of a static type of language.

\subsection{Keynes’ Argumentative Strategies}

Another feature that was taken into consideration in this project was the kind of argumentative strategies adopted by the author in his reasonings about and explanations of the main macroeconomic phenomena. The analysis has clearly shown a close link between the author's language and heuristic method, which surfaces especially in his drafting plan. Although he is willing to organize the text according to the theoretical foundations of economics, this relationship between method and composition seems at times to create major difficulties, especially whenever the drafting pattern clashes with the non-sequential nature of his theoretical argumentation. The conflict derives from the fact that Keynes' analytical model is based on the notion that there is an organic interdependence between economic variables that cannot be adequately accounted for by the atomistic approach typical of classical theory. Keynes explains the systematic nature of his new method at a point in the GT where the new methodology is introduced:

(5) The object of our analysis is, not to provide a machine, or method of blind manipulation, which will furnish an infallible answer, but to provide ourselves with an organised and orderly method of thinking out particular problems; and, after we have reached a provisional conclusion, by isolating the complicating factors one by one, we then have to go back on ourselves and allow, as well as we can, for the probable interactions of the factors amongst themselves. (GT: 297)

Keynes' heuristic method thus proposes to overcome the restricted confines of classical economics by dealing with two opposing needs. On the one hand, the need to examine economic variables as

\footnotetext{
${ }^{3}$ For an examination of Keynes’ economic method see Carabelli / Cedrini (2014).
} 
isolated elements; on the other, the need to draw on independent studies to show the close interrelations among the various variables examined. This alternation between linear atomistic analyses and complex systemic integration is reflected in the expository form of the book. At that level, there are recurrent cross-references to other parts of the book. For Chick this technique resembles the expository language of cinema, as "Keynes's method is more like a film, a moving picture, made from snapshots (as films are), each snapshot systematically related to what has gone before. It is a story full of flashbacks - and flashes forward” (1983: 14).

By continually referring the reader to other parts of the GT, Keynes balances the complexity and systemic interdependence of the various parts of his analysis with the linear progression of his monograph. This is illustrated by several examples of how Keynes moves away from the text in order to help the reader to grasp the overall scheme of the book. In so doing he signals which aspects of a given economic problem deserve attention in later chapters:

(6) The theory of wages in relation to employment, to which we are here leading up, cannot be fully elucidated, however, until chapter 19 and its Appendix have been reached. (GT: 18)

(7) We shall return to the aggregate supply function in chapter 20, where we discuss its inverse under the name of the employment function. But in the main, it is the part played by the aggregate demand function which has been overlooked; and it is to the aggregate demand function that we shall devote Books III and IV. (GT: 89)

(8) It may be mentioned, in passing, that the effect of fiscal policy on the growth of wealth has been the subject of an important misunderstanding which, however, we cannot discuss adequately without the assistance of the theory of the rate of interest to be given in Book IV. (GT: 95)

In other parts of the book, before launching into the analysis of the various elements of a given theory, Keynes briefly outlines it even though he is aware that the reader may find it difficult to understand a new theory before it is presented in full and its terminology explained:

(9) A brief summary of the theory of employment to be worked out in the course of the following chapters may, perhaps, help the reader at this stage, even though it may not be fully intelligible. The terms involved will be more carefully defined in due course. (GT: 27)

On occasion Keynes interrupts the discussion of economic variables, leaving the exposition suspended, in order to introduce further explanations which the reader might consider as mere digressions:

(10) In this and the next three chapters we shall be occupied with an attempt to clear up certain perplexities which have no peculiar or exclusive relevance to the problems which it is our special purpose to examine. Thus these chapters are in the nature of a digression, which will prevent us for a time from pursuing our main theme. (GT: 37)

Occasionally Keynes finds himself unable to sustain the discussion of an issue and is forced to introduce certain aspects or terminology without being able to clarify them adequately:

(11) In some passages of this section we have tacitly anticipated ideas which will be introduced in Book IV. (GT: 112)

(12) It would seem (following Mr Kahn) that the following are likely in a modern community to be the factors which it is most important not to overlook (though the first two will not be fully intelligible until after Book IV has been reached. (GT: 119) 
The frequent presentation of new material combined with reference to previously discussed matters gives Keynes' work its unique character, which is very different from that of the traditional academic essay. Chick finds that the GT's expository approach is in many ways similar in structure to a play:

To make clear the structure of the General Theory, it might be helpful to compare the book to a play. When characters go off-stage in the theatre, you do not presume them to be dead - they are likely to pop back at any time. The General Theory is rather like that. Early on (G.T. Chapter 3) you are given a sketch of the plot, but it is only much later (G.T. Chapters 19-21) that the full story is revealed. (Chick 1983: 28)

Another central feature which was identified by our analysis is the utility of insights, which allow both reader and writer to catch aspects which might escape notice using only deductive observational methods. Such insights are important for understanding the text as well as its composition process, as they point to the line of reasoning and also clarify its details and applications. The act of writing is itself part of Keynes' heuristic effort, which allows him to keep ahead by means of chains of intuitions and deductions when uncovering the facts of economic life. This explains his frequent recourse in argumentation to hypothetical clauses preceded by a premise and followed by a conclusion, with an argumentative pattern of the kind: Let (Z) be... Now if..., thus... An alternative variant starts with the observation of some 'facts of experience' or features of 'human nature', from which the author draws his conclusions with expressions such as If this is true, it follows that...

The act of writing itself is part of Keynes' heuristic activity which allows him to keep moving ahead, by means of chains of intuitions and deductions, in the uncovering and understanding of the facts of economic life. We can see the result of this process not only in what he has to say about the influence the act of writing has on him, but also in his claim that the object of his creative effort has its own separate existence independent of the person of the writer. As he says in the Preface:

(13) This book, on the other hand, has evolved into what is primarily a study of the forces which determine changes in the scale of output and employment as a whole; and whilst it is found that money enters into the economic scheme in an essential and peculiar way, technical monetary detail falls into the background. (GT: xxii, emphasis added)

Claims about the creative and interpretive power of both the author's and the reader's intuitive abilities underline what we mooted earlier, that the polyvalency of the GT was not a chance matter, but the upshot of a deliberate choice. Once again, we cannot help noting how Keynes sets himself to upset the traditional canons of interpretation and to defeat the reader's expectations.

\subsection{Emotional Involvement}

A predictable feature of specialized discourse is the high referential value of its texts, combined with limited emotional involvement on the part of readers. In Walton's words:

Traditionally, appeals to emotion in argument have been distrusted and even labeled categorically as logical fallacies. There is a common tendency to contrast 'impartial reason' with 'the passions' and to distrust the latter in reasoned argument. And this tendency is often affirmed in logic texts where appeals to emotion have been treated as inherently illogical and subject to strong censure. (Walton 1989: 82-83)

Our analysis, however, has shown that this assumption does not seem to hold for Keynes. He seeks to convince the audience not only through sound demonstration and factual evidence but also using plausible, persuasive argumentation that is not necessarily irrefutable. For this purpose, figurative and emotive language, which is normally considered alien to the epistemology of specialized discourse, is often employed. Indeed, when reading the GT one immediately perceives that the conflictual element implicit in all argumentative texts (Cf. Gotti et al. 2002) is here taken to extremes. This impression is 
confirmed by a reading of Keynes' correspondence with colleagues and friends, which reveals his determination to highlight conflictual aspects in the GT. In reply to Ralph F. Harrod, he announces that "I want, so to speak, to raise a dust; because it is only out of the controversy that will arise that what I am saying will get understood”. (CW XIII: 548)

Keynes' decision to 'turn up the volume' (Martin 2000) and adopt a highly conflictual authorial stance (Hyland 2005) is coherently maintained in his writing, as reflected by the harsh, polemic tone which characterizes his use of words and figures of speech, especially in the Preface and in Chapter 12. The choice of lexis demonstrates the author's ability to criticize contemporary economic theory and express new ideas in an extremely figurative, connotative language. Keynes' use of words suggests to readers that his work is conceived as a reaction against current theory, "a long struggle of escape from habitual modes of thought and expression" (GT: xxiii). He has reached a state of freedom from the preconceived doctrines of the past and feels "to be breaking away from this orthodoxy, to be in strong reaction against it, to be escaping from something, to be gaining emancipation" (GT: xxiii). He wants to make a clean break with the past, as the theory prevalent among academics has proved to be "misleading and disastrous" (GT: 3). The discourse of conflict is used by Keynes not only to word his controversies with other economists but also to describe divergences of opinion among them. The following statements, for instance, are used by Keynes to express the differences between Malthus and Ricardo:

(14) Malthus, indeed, had vehemently opposed Ricardo's doctrine [..]. Ricardo conquered England as completely as the Holy Inquisition conquered Spain. [...] The other point of view completely disappeared. [...] The great puzzle of effective demand with which Malthus had wrestled vanished from economic literature. [...] It could only live on furtively, below the surface, in the underworlds of Karl Marx, Silvio Gesell or Major Douglas. The completeness of the Ricardian victory is something of a curiosity and a mystery. (GT: 32)

Chapter 12 is especially representative of Keynes' emotional tone. Its aim is to convince readers of the unreliability of economic decisions concerning investments, due to the level of irrationality in investors' behaviour. To underline the irrational element, Keynes argues "on a different level of abstraction from most of the book" (GT: 149), rather than adopting a logical line of reasoning. In particular, he decides to adopt lexical items with a strong emotional load, generally indicating excessive presence or absence of certain traits. The most frequent fields where such excess occurs are reasonableness (foolish, unreasoning, vagaries, irrational), quantity (disproportionately, outstanding, extreme, negligible, scanty, slight, non-significant), size (extensive, enormous, vast), norm (abnormal, anti-social), gravity (disastrous, collapse, serious) and force (violently, prevailing, predominates, predominance). The markedness of Keynes' text is also denoted by the incongruous semantic fields from which many lexical items are taken. Some of those found in Chapter 12 are religion (temptation, orthodox, fetish, doctrine, faith, sins), physical elements (sanguine, instinct, animal spirits) and war (gun, battle, assailed). Even when lexical items do not denote excess or unnaturalness, they are often made more marked by the use of intensifying or attitudinal premodifiers which emphasize certain semantic traits or comment on them. The main of such premodifying expressions in the GT are decisively, very, highly, most, seriously, much more, intolerably, over-, entirely and scarcely. On other occasions the author underlines the degree of validity of his assertions by means of attitudinal adverbials such as obviously, surely, indeed, of course, frankly and in truth.

Apart from the linguistic items described above, Keynes makes use of various rhetorical devices to emphasize emotiveness. One of such means is reinforcement, whereby the semantic load of a lexical item is strengthened by a synonym or a related term. Examples include: vague and scanty, very slight and often negligible, ephemeral and non-significant, intolerably boring and over-exacting, inaccessible and very expensive, permanent and indissoluble, supplemented and supported. Sometimes the sequence is extended, with the addition of a third element whose function is to increase the effect of the whole string: eccentric, unconventional and rash; disastrous, cumulative and far-reaching repercussions. 
Often the succession of elements is not a mere repetition of the same concept but acts as a boosting of its semantic value, as in a crescendo:

(15) We have to admit that our basis of knowledge for estimating the yield ten years hence of a railway [...] amounts to little and sometimes to nothing. (GT: 149-150)

(16) Day-to-day fluctuations in the profits of existing investments [...] tend to have an altogether, and even an absurd, influence on the market. (GT: 153-154)

(17) Thus if the animal spirits are dimmed and the spontaneous optimism falters [...] enterprise will fade and die. (GT: 162)

Another rhetorical device often employed by Keynes to highlight the emotional tone of his discourse is contrast. The whole chapter is built around a series of contrasts that emphasize the great discrepancy between the common rational expectations connected with investment and the irrational choices made by investors in reality. The linguistic items that encode the main contrasts pointed out in the chapter show the progress of Keynes' argumentation about long-term investment:

$\begin{array}{ll}\text { existing facts } & \text { future events } \\ \text { reasonable } & \text { foolish } \\ \text { cold calculation } & \text { take a chance } \\ \text { fixed investments } & \text { liquid investments } \\ \text { revival } & \text { collapse } \\ \text { strengthening } & \text { weakening } \\ \text { enterprise } & \text { speculation } \\ \text { mathematical expectation } & \text { spontaneous optimism } \\ \text { action } & \text { inaction }\end{array}$

A further rhetorical device used by Keynes to make his argumentative text more emotional is metaphor. ${ }^{4}$ What creates the emotional effect is once again the use of lexical items drawn from fields not directly connected to economics; moreover, these all bear strong connotations and are therefore likely to arouse an emotional response in the reader. The commonest are religion (the fetish of liquidity, the sins of the London Stock Exchange), war (dark forces of time and ignorance which envelop our future, this battle of wits, to defeat the forces of time), corporal states (to feed the maws of the professional, gambling instinct), natural states (a steady stream of enterprise, a whirlpool of speculation) and playing games (businessmen play a mixed game, the game of professional investment, gambling instinct). The last of these is the one most frequently employed by Keynes, as it enables him to convey his argument in a most convincing way: by wording his persuasive strategy in emotional rather than rational terms, Keynes selects the analogy INVESTMENT = GAME as the most memorable way to represent the irrationality and unpredictability of long-term investments. His thesis is based on the assumption that investment decisions do not merely rely on objective factors, but are conditioned by subjective elements which cannot always be predicted with absolute certainty and therefore make the whole investment system very unreliable. Investors often ignore or are ignorant of classical economics, and so behave in ways which are quite unpredictable and sometimes irrational. For example, among the features which Keynes attributes to them are that

(19) [they] know almost nothing whatever about what they are doing. They do not possess even the rudiments of what is required for a valid judgment, and they are the prey of hopes and fears easily

\footnotetext{
${ }^{4}$ The importance of the use of a metaphorical language in economic argumentation has frequently been pointed out; see, among others, Richardt (2005: 147-158).
} 
aroused and as easily dispelled. This is one of the odd characteristics of the capitalist system under which we live, and is not to be overlooked. (GT: 323)

Investors' choices are thus determined by their expectations of possible future earnings that do not depend on objective evaluations so much as on optimistic or pessimistic views of future stock market trends. Such irrationality does not only characterize the layman but also financial brokers, as their job is to buy stocks and shares whose quotations are expected to rise, and sell those whose value is expected to fall. This sort of behaviour is likened to a game by Keynes:

(20) It is, so to speak, a game of Snap, of Old Maid, of Musical Chairs - a pastime in which he is victor who says Snap neither too soon nor too late, who passed the Old Maid to his neighbour before the game is over, who secures a chair for himself when the music stops. These games can be played with zest and enjoyment, though all the players know that it is the Old Maid which is circulating, or that when the music stops some of the players will find themselves unseated. (GT: 155-156)

This line of interpretation is strengthened by the many metaphors related to the semantic field of gambling that occur throughout the text:

(21) the affair was partly a lottery (GT: 150)

a mixed game of skill and chance (GT: 150)

a game of Snap (GT: 155)

a pastime (GT: 156$)$

these games can be played with zest and enjoyment (GT: 156)

professional investment may be likened to those newspaper competitions (GT: 156)

large profits to be gained from the other players (GT: 156)

unperturbed by the prevailing pastime (GT: 156)

predominate in their influence over the game-players (GT: 156)

the game of professional investment (GT: 157)

the gambling instinct (GT: 157)

the higher return from the pastime (GT: 157)

a by-product of the activities of a casino. (GT: 159)

The number of metaphors that recall gambling is so high that their choice is clearly the result of the author's decision to evoke in the reader's mind an immediate association between the notion of investment and aspects connected to gambling, such as unpredictability, risk, etc.

\subsection{Reader Involvement}

It is generally considered inappropriate for authors of specialized texts to lead their argumentation in a vague or incomplete way. Keynes, however, seems to contradict this general criterion. Indeed, in the GT he shows a keen awareness of the great expressive potential of language and successfully exploits it in his economic argumentation, especially to engage readers in a cooperative effort when interpreting his text. Keynes' own words seem to confirm this hypothesis:

(22) It is, I think, of the essential nature of economic exposition that it gives, not a complete statement, which even if it were possible, would be prolix and complicated to the point of obscurity but a sample statement, so to speak, out of all the things which would be said, intended to suggest to the reader the whole bundle of associated ideas, so that, if he catches the bundle, he will not in the least be confused or impeded by the technical incompleteness of the mere words which the author has written down, taken by themselves. [...] An economic writer requires from his reader much goodwill and intelligence and a large measure of co-operation. (CW XIII: 470) 
In this passage, Keynes interestingly describes the argumentation of economists as a succession of sample statements which work by suggesting to the reader a whole bundle of associated ideas. In this way the text provides readers with cues for personal associations, rather than unambiguous conclusions determined by an orderly set of premises and reasonings. Thus, we can clearly see that even the ambiguity of certain passages of the GT (cf. Section 2.1 above) is not accidental but due to a deliberate choice on the author's part. Keynes meant this to be an 'open work' (Eco 1989), allowing readers to play an active role in interpreting his new theory bringing the author's creation to fruition. Its final form was meant to be flexible, capable of being read in a variety of ways and open to the critical, interpretive agency of the reader. A year after publication, Keynes offered the following comment:

(23) I am more attached to the comparatively simple fundamental ideas which underlie my theory than to the particular forms in which I have embodied them, and I have no desire that the latter should be crystallised at the present stage of the debate. If the simple basic ideas can become familiar and acceptable, time and experience and the collaboration of a number of minds will discover the best way of expressing them. (CW XIV: 111)

As Keynes himself admits, the reader is asked to offer not just the usual sort of cooperation, but a much higher level of intuitive involvement and goodwill. The GT is therefore one of the few non-literary texts whose author, willingly and knowingly, assigns to readers not merely the role of decoders and recipients of his views but a far more demanding role as his collaborators in working out the final form and the exact meaning of a new economic theory.

\section{Conclusion}

The investigation carried out by our research project thus clearly explains the main reasons why economists have found difficulties in understanding Keynes' discourse and have expressed criticism of its textual obscurity and ambiguity, which have caused both misunderstandings and divergent interpretations of the GT. The analysis of the text - supported by the reading of Keynes' other texts and his correspondence with his colleagues - clearly suggests that he did not always shape his arguments in a way that would meet the standard expectations of his readership or of the economic community in general. The strategy that he adopted was risky and was likely to draw bitter criticisms and unpleasant misunderstandings. Indeed many misreadings of Keynes' work stem from an inability to accept the individuality of his choices and decisions, which at times violate the more predictable features of economics discourse. Also his views of terminology are certainly in a way innovative and prove to be in line with, and even follow from, the other theoretical and methodological novelties of the GT. By allowing his own words to have a number of meanings, Keynes has changed the very concept of the language of economics and deprived it of the features of univocity and singleness of reference.

Another trait of individuality found in Keynes' text is the importance that he attributes to the use of a metaphorical language in economic argumentation. This rhetorical function has been seen in contrast with the view that many economists have of the discourse of their science whose aim should be the persuasion of one's interlocutors by means of plain facts and objective statements. Keynes' conviction of the important role that rhetoric plays in argumentative texts derives from his epistemological beliefs that the success of a theory relies on its being accepted by its addressees rather than on objective evidence or explicit proof.

Another element of Keynes' writing strategy that this research has highlighted is the important role that he attributes to reader engagement. Indeed the impression of obscurity and ambiguity that the GT sometimes seems to suggest to the reader is not due to a fault in Keynes' writing or confusion in his theoretical reasoning, but rather to the author's decision to allow readers a large degree of personal interpretation. Moreover, by provoking a vast and long-lasting debate, the alleged obscurity and 
ambiguity of certain parts of the book have enabled the Keynesian theory to be better defined and completed by the exegetic efforts made by the various readers.

Apart from highlighting Keynes' mastery of the linguistic and metalinguistic principles which have favoured the efficacy of his persuasiveness in economic argument, the results of this analysis have also led us to two more general considerations: on the one hand, the issues identified here show that linguistic insights and explanations deriving from a clear focus on the conditions of production and reception of the texts can be of great help to disciplinary experts - in this case economists - in attaining a more correct interpretation of a given text. On the other hand, this sort of analysis is also a source of valuable evidence for applied linguists, provided their findings are continuously confronted with the expert professionals in a process of feedback and triangulation. In this particular case, the collaboration between experts and linguists has promoted a better definition of the method of inquiry and hence of the argumentative strategies adopted by Keynes. In spite of their lack of adequate knowledge of the economic discipline, the applied linguists' contribution to this collaborative project has not only facilitated the economists' interpretation of this important text but has also enhanced a deeper understanding of their own professional discourse.

\section{References}

Carabelli, Anna M. \& Cedrini, Mario A. 2014. Keynes's General Theory, Treatise on Money and Tract on Monetary Reform: Different Theories, Same Methodological Approach?. The European Journal of the History of Economic Thought 21/6, 1060-1084.

Chick, Victoria 1983. Macroeconomics after Keynes. Oxford: Philip Allan.

Chick, Victoria 2006. The General Theory is Difficult; Whose Fault is That? Revista de Economia 32/2, 135-151. <http://ojs.c3sl.ufpr. br/ojs2/index.php/economia/article/viewFile/7732/5505>.

Cicourel, Aaron V. 1992. The Interpenetration of Communicative Contexts: Examples from Medical Encounters. In Duranti, Alessandro / Goodwin, Charles (eds) Rethinking Context: Language as an Interactive Phenomenon. Cambridge: Cambridge University Press, 291-310.

Clarke, Angus 2005. Commentary 1: Professional Theories and Institutional Interaction. Communication \& Medicine 2/2, 189-191.

Eco, Umberto 1989. The Open Work. Cambridge, MA: Harvard University Press.

Gotti, Maurizio 2011. Investigating Specialized Discourse. Bern: Peter Lang.

Gotti, Maurizio; Heller, Dorothee \& Marina Dossena (eds) 2002. Conflict and Negotiation in Specialized Texts. Bern: Peter Lang.

Hyland, Ken 2005. Metadiscourse. London: Continuum.

McCloskey, Donald 1988. The Consequences of Rhetoric. In Klamer, Arjo; McCloskey, Donald and Robert Solow (eds) The Consequences of Economic Rhetoric. Cambridge: Cambridge University Press, 280-293.

Martin, James R. 2000. Beyond Exchange: APPRAISAL Systems in English. In Hunston, Susan \& Geoffrey Thompson (eds) Evaluation in Text: Authorial Stance and the Construction of Discourse. Oxford: Oxford University Press, 142-175.

Naess, Arne 1981. Communication and Argument, Oslo: Universitets-Forlaget.

Patinkin, Don 1976. Keynes' Monetary Thought. Durham, NC: Duke University Press.

Patinkin, Don \& Leith, J. Clark (eds) 1977. Keynes, Cambridge and 'The General Theory'. London: Macmillan.

Richardt, Susanne 2005. Metaphor in Languages for Special Purposes. Frankfurt am Main: Peter Lang. 
Sarangi, Srikant 2002. Discourse Practitioners as a Community of Interprofessional Practice: Some Insights from Health Communication Research. In Christopher N. Candlin (ed.) Research and Practice in Professional Discourse. Hong Kong: City University of Hong Kong Press, 95-135.

Sarangi, Srikant 2015. Experts on Experts: Sustaining 'Communities of Interest' in Professional Discourse Studies. In Gotti, Maurizio / Maci, Stefania / Sala, Michele (eds) Insights into Medical Communication. Bern: Peter Lang, 25-47.

Walton, Douglas N. 1989. Informal Logic. Cambridge: Cambridge University Press.

Yeager, Leland B. 1986. The Keynesian Heritage in Economics. In Burton, John et al. (eds) Keynes’s General Theory: Fifty Years On. London: The Institute of Economic Affairs, 25-44. 